\title{
What advice is given to newly qualified doctors on Twitter? An analysis of \#TipsForNewDocs Tweets
}

\author{
Abstract \\ Introduction: Twitter is a social media platform where users post very brief messages which can be \\ rapidly communicated across wide geographical areas and audiences. Many doctors use Twitter for \\ personal as well as professional communications and networks. The \#tipsfornewdocs hashtag is used on \\ Twitter to give advice to newly-qualified doctors as they commence their careers. This study explores \\ the nature and focus of such advice.
}

Methods: An analysis of Twitter activity containing the \#tipsfornewdocs hashtag was performed using Symplur healthcare analytics software. Tweets from a peak 48-hour period in 2016 (immediately preceding the first day of work for newly qualified UK doctors) were studied. The geographical location and professional background of participants was categorized and the content of tweets was subjected to thematic analysis. In a 48 hour period between 01/08/2016 and 02/08/2016, 661 unique \#tipsfornewdocs tweets were posted. 621 (93.9\%) were posted from participants in the UK; 522 (78.9\%) were by doctors, with the remainder coming from allied healthcare professionals and patients.

Results: The majority of included tweets focused on aspects of professional development, improving personal or professional knowledge, particularly tacit knowledge, or developing 'know-how'. These aspects of professional knowledge have previously been described by Eraut (1994) as fundamental to professional education and training. A significant subset of tweets instead focused on accelerating socialization into the profession: another essential step in joining professional communities. The tweets relating to socialization were often humorous and casual in nature.

Conclusions: Despite their brief and often jocular nature, \#tipsfornewdocs tweets provided meaningful advice for newcomers to the profession, often focusing on tacit learning and professional socialization. Hashtag-driven enquiries can be a valuable and time-efficient way of accessing and sharing tacitly held knowledge. Social media content analysis can provide valuable insights into key educational issues. 


\section{Introduction}

There has been much interest in the participation of doctors in social media sites. Although there have been concerns raised about professionalism, public trust ${ }^{1}$ and breaches of confidentiality ${ }^{2}$, there has also been recognition that social media has the potential to increase the engagement of healthcare students, clinicians and the public by expanding networks, sharing learning and providing moral support $^{3}$. Following guidelines by regulators ${ }^{4,5,6}$, and as usage has matured, it has become clear social media has a role in supplementing the traditional medical education experience ${ }^{7}$.

Studies have explored the roles of a range of social media platforms in medical education, including Twitter $^{7}$, Facebook ${ }^{8}$, Snapchat ${ }^{9}$, Instagram, and Whatsapp ${ }^{10}$. Although initial studies have been optimistic about the effectiveness of using these platforms, there have been concerns about the lack of editorial oversight of materials and the possibility that popular online individuals may have disproportionately high influence ${ }^{11}$. Moreover, a recent systematic review on the use of social media in graduate medical education found that although individual studies have had mixed findings, the quality of studies has been modest at best ${ }^{12}$.

Twitter is a popular, free-of-charge, social media platform with 313 million active users world-wide, who communicate through micro-blogs of up to 140 characters, called 'tweets'13. Hashtags (a word or phrase starting with the '\#' symbol and continuing without spaces) are often added to tweets to allow other users to search for information and follow or contribute to discussions on particular topics. Twitter has been influential in the documentation of, and commentary on, numerous recent news events and Twitter data has been widely used across a variety of sectors, including in political elections ${ }^{14}$, predicting stock market prices ${ }^{15}$ and measuring disease outbreaks ${ }^{16}$.

In the healthcare sector Twitter data has been used for a wide range of purposes including measuring patient-perceived quality of care in hospitals ${ }^{17}$ and exploring debate and opinion on specific areas of health. In medical education settings there has also been recognition that Twitter can deliver concise and newly emerging clinical information in a highly interactive way ${ }^{18}$. Specific scenarios, including 
international Twitter journal clubs ${ }^{19}$ and the use of Twitter during medical conferences ${ }^{20}$ have received interest.

A particularly important feature of Twitter is the ability to communicate across geographical areas and reach a wide audience. Due to the nature of social networking, many doctors use Twitter for personal as well as professional communications and friendships and professional networks are an important benefit for many doctor users ${ }^{21}$. Many hashtags have emerged that link together conversations between doctors, fostering a sense of community. One such hashtag is \#tipsfornewdocs, which has emerged to provide advice to newly qualified doctors who are preparing to embark on their first clinical roles. The originator of this movement is not clear, although it was submitted to the Symplur for tracking under the Healthcare Hashtag Project by the Twitter user @_NMay. Although this hashtag has been publicised and congratulated ${ }^{22}$, it has not yet been examined in a systematic way.

Whilst previous research has explored the communication between doctors on Twitter $^{23}$, particularly in formal education contexts ${ }^{20}$, there is currently a lack of evidence about how more informal or tacit learning and advice is shared on such platforms. \#tipsfornewdocs, with its focus on advice for novices, is targeted at a significant period of learning and socialisation for doctors ${ }^{24}$. It is likely that such advice may feature aspects of professional knowledge that are rarely formally documented or shared. This is of interest in medicine where the 'hidden curriculum' is seen as a powerful influence on learning that is difficult to capture and measure ${ }^{25}$ and where the rapid re-contextualisation of knowledge ${ }^{26}$ and becoming part of a high performing team are central to safe and effective practice as a new doctor.

In this study we sought to categorise the content of Tweets posted using \#tipsfornewdocs to uncover the purpose and nature of advice issued to newcomers to the medical profession.

\section{Methods}

The Symplur healthcare analytics site ${ }^{27}$ allows users to generate customisable participation metrics. This feature was used to generate a graph of tweet activity using the \#tipsfornewdocs hashtag from $1^{\text {st }}$ January 2010 to August 2016, shown in figure 1. In light of the peaks of activity in early August and the fact that the first week of August is when newly qualified doctors in the UK typically begin their first job, an in-depth search was performed on using Symplur to gather all tweets posted in a 48-hour period 
between $1^{\text {st }}$ August 2016 (00:00) and $2^{\text {nd }}$ August 2016 (23:59). These tweets were exported as a transcript. Tweets not meeting the inclusion criteria, highlighted in table 1, were excluded. This sorting allowed duplicate material, known as retweets, to be removed. As the emphasis of this paper was on inter-professional communication, tweets from organisational or group accounts were not included as these typically focused on marketing products or services.

Included tweets were coded using a data extraction template on Microsoft Excel, which was modified after a pilot was tested on 50 random tweets. This template was used to record the professional role of the individual posting the tweet, their country of origin and the verbatim text in the tweet. Information about Twitter users was collected using a combination of their online biographies, user names, and following links to websites. Location of tweets was determined by the country listed in the biography of the user. Senior doctors were defined as those who had completed postgraduate clinical training.

Tweets were analysed independently by two authors (MR and DM), who read and then re-read them before assigning an identifying code to each tweet using language directly from the post to retain the original meaning. Given the inherent brevity of tweets, there was typically a single main message for an individual post. The authors also categorized the style of tweet (e.g. whether it was intended to be humorous) and generated tentative themes. The three study authors then reviewed these initial themes identifying that most posts related to either one of the four components of Eraut's model of professional knowledge ${ }^{28}$ or to the process of socialisation into the workplace. A thematic framework was devised using these four categories of professional knowledge: propositional knowledge (theories and concepts), personal knowledge (interpretations of experience), process knowledge (delivery methods), and know-how (intimate system knowledge), and with an additional category of socialisation. Two authors (MR and DM) independently reviewed the tweets again to ensure the framework captured the breadth of topics covered in the tweets and all authors agree on the final coding, with consensus meetings used to resolve areas of disagreement.

\section{Results}

The \#tipsfornewdocs hashtag was first used in July 2011 and by $1^{\text {st }}$ September 2016, it had featured in 52,713 tweets by a total of 17,706 participants. As demonstrated in figure 1 , activity has been gradually increasing throughout this time, with clear peaks every year between the months of June and September. The in-depth search between $1^{\text {st }}$ August 2016 and $2^{\text {st }}$ August 2016 yielded 2742 Tweets by a 
total of 1407 participants. Of these, 2081 were excluded and 661 unique \#tipsfornewdocs tweets were included in the qualitative analysis (see Figure 2).

621 (93.9\%) tweets were posted from the UK and the remainder were from North America. 280 (45.0\%) tweets were by junior doctors, $242(39.0 \%)$ were by senior doctors, $87(13.2 \%)$ were by non-medical clinicians such as nurses and pharmacists, and the remaining 52 (7.9\%) were from patients and members of the public. 16 (2.4\%) tweets included links to websites, which included personal blogs and journal articles. Many included tweets contained additional hashtags (\#bethebest, \#medicine, \#mentalhealth \#psychiatry, \#patient, \#palliative). Some hashtags appeared more than once amongst included tweets (\#NHS - 2, \#MedEd - 2, \#teamwork - 2, \#juniordoctor - 3, \#hellomynameis - 8).

In total, twenty sub themes were identified. Of these, fifteen related to the four main themes of sharing professional knowledge: propositional, personal. process and know-how. A further five sub themes related to the main theme of professional socialisation. A visual model of this classification is described in figure 3 and table 2 provides frequencies and example tweets for each theme. Descriptions of each theme are provided below.

\section{Sharing of Professional Knowledge}

\section{- Propositional knowledge}

Four themes related to theoretical aspects of professional knowledge. The most frequently occurring of these relates to patient-centred care. Tweets in this category related to understanding patient's values and perspectives and integrating these into their practice to become more holistic practitioners. A distinct but related theme concerned learning from patients. Posts in this category were from both junior and senior doctors, as well as a distinct group of 'expert patients' and patient advocates. Indeed, a significant proportion of tweets from patients offered advice about patient-centred care and taking time to listen carefully to what patients had to say.

Another propositional knowledge theme related to the importance of introducing yourself. These posts related to introductions to both colleagues and patients and often included an additional hashtag of \#hellomynameis - a popular quality improvement campaign launched in the UK in August $2013^{29}$. A final theme linked to this category concerned emotional intelligence. These posts describe some of the unique and subtle challenges that arise in the course of medical practice and provide insights into how they should be approached. 


\section{- Personal knowledge}

Four themes related to professional knowledge acquired through experience. The first is about asking for help. These posts came from both junior and senior doctors as well as other healthcare professionals and this was the commonest theme of tweets using this hashtag overall. Many tweets in this category urged new doctors to avoid feeling scared or embarrassed by their questions. A related theme was about valuing non-medical colleagues, such as nurses, paramedics, pharmacists and other members of the multidisciplinary healthcare team. Of note, these tweets were often posted by members of these professions themselves, offering their perspectives on how doctors should behave and typically, what support was available to them from the wider team.

Another theme in the personal component was about maintaining one's own physical and mental wellbeing. These tweets emphasised the importance of rest and holidays and making time for food and restroom breaks during busy shifts. The final personal theme was about personal values and prompted new doctors to act kindly and professionally. This theme was about moral values and differed from the emotional intelligence theme mentioned above, which was more to do with practically navigating uncomfortable scenarios faced by doctors.

\section{- Process knowledge}

Four further themes related to professional knowledge about occupational processes and information about how to get tasks done. The first theme provided advice about clinical skills, including examination and procedures that new doctors would be expected to undertake. The tone of the advice varied from light-hearted to sombre and consisted largely of informal tips.

The importance of accurate, rigorous and legible documentation was a further theme in this component and included both specific and general pointers about how to write in medical notes and patient drug charts.

Another theme in this category was about recognising unwell patients. These posts encouraged new doctors to trust their instincts and offered solutions to get help when in this position. The focus of this theme was escalating care early when there was a sense that a clinical situation may deteriorate.

The final theme in this component was about making use of educational opportunities and these tweets prompted new doctors to remember their own training needs once submerged into the workplace, as well as advertising specific on- and off-line educational resources such as libraries, blogs, and podcasts. 


\section{- Know-How}

Three themes related to sharing intimate professional knowledge of how the workplace operates. The first was about essential items for junior doctors, such as working pens, stethoscopes, security access cards and other important objects. The second covered the key aspects intricacies of making referrals to other specialties or requesting investigations. Requesting radiological imaging and discussing requests with radiologists was the subject of many tweets within this category. The final theme promotes organisational skills as a key way to counter the complexity of the role of a junior doctor.

\section{Professional Socialisation}

Five themes fell outside the domain of sharing professional knowledge and relate instead to the socialisation process that initiates new professionals to the workplace. The most commonly occurring of these concerned humour. These posts were typically from doctors and consisted of advice that was unmistakably (and therefore entertainingly) inappropriate as well as jokes relating to the use of medical terms.

A second theme in this category was good luck wishes to new doctors, often from senior doctors welcoming them to the profession. A related theme was of camaraderie and these posts encouraged new doctors to look after one another and be considerate. This theme included both practical advice, such as tasks that should not be handed over to colleagues at the end of a shift, as well as more general advice on work ethic and teamwork.

A further theme include advice on how to fit in and behave in the workplace, including unsaid conventions and survival tips on what to say and wear. The final theme relating to the socialisation process relates to behaviour with senior, non-peer medical professionals. As tweets were predominantly from the UK, most posts in this category related to how to act around 'consultants', the most senior members of the medical team. The advice included how to avoid getting on the wrong side of seniors, but also how to access mentorship and idiosyncrasies of medical specialties, especially anaesthesia and radiology.

\section{Discussion}

This study considers the advice given to new doctors through the \#tipsfornewdocs hashtag on Twitter. It demonstrates how social media provides a channel to enable quick and efficient sharing of tacit learning across newcomers and allow individuals from inside and outside the profession to equitably share their 
experiences and guidance for newly qualified doctors. The content of the tweets was varied in both topic area and style and included both professional knowledge and support for the process of socialisation to the profession. The majority of the advice concerned tacit knowledge or 'shortcuts' that might accelerate the process of becoming a member of healthcare teams.

The preparedness of newly qualified doctors is a matter of considerable interest in the medical community $^{30}$, particularly in light of evidence that patient mortality is higher during the first few days that newly qualified doctors are in work ${ }^{31}$. A UK study that used audio recordings to monitor newly qualified doctors' experiences reported that the key challenges of being a new doctor were dealing with newly gained responsibility, managing uncertainty and working in multi-professional teams ${ }^{32}$. It is reassuring that these issues featured heavily in the tweets in this study. A study that asked first year doctors to reflect on their own development found that 'real world'-skills such as communication, team working were the most important early challenges ${ }^{33}$, a more recent study suggested that decisionmaking, relationships with senior staff and managing time ${ }^{34}$ were the most important issues for newcomers. These findings were remarkably consistent with the content of posts using \#tipsfornewdocs, reflecting the authenticity of the activity as a system of sharing professional advice.

As education scholars have noted, socialisation is a complex process involving reciprocal and reinforcing relationships between experiences of professional inclusivity and social exclusivity that creates a defined sense of professional identity ${ }^{35,36}$. A number of emergent themes in this study were grouped into this category. Previous studies of the use of Twitter in medical education have noted that it creates a space for both clinicians and patients to interact without the usual hierarchies ${ }^{7}$. It can be challenging in medicine to know when it is acceptable to use humour and how to fit in to the medical team, especially with senior colleagues. The fact that this complex and nuanced information was shared in such an informal and relaxed way using this hashtag suggests that social media is potentially a powerful forum to accelerate this socialisation process for new doctors.

Pursuing professional development and continuing medical education, expanding networks and providing moral support to colleagues have all been identified as potential benefits of doctors engaging with Twitter ${ }^{3}$. Previous research has established that doctors manage an online persona when using Twitter $^{37}$, which may help to explain the frequent use of humour in tweets from doctors. A literature review on the use of Twitter in medical education advised educators should seek to create a 'real life' context for students and prompt self and group reflection ${ }^{38}$. This seems to have been adopted in the \#tipsfornewdocs guidance observed in this study. Although an Australian national survey found that 
many doctors were hesitant to engage fully with social media due to concerns about professional and ethical challenges ${ }^{39}$, many tweets in this study demonstrated that doctors were willing to discuss sensitive issues in their Twitter network.

The strengths of this study include the systematic approach to identifying and coding tweets and the independent categorisation by two medically qualified reviewers. The medical backgrounds of all study authors and additional social science background of one author (DG) provided a richness to the data analysis and allowed the research team to appreciate the nuanced nature of inter- and intraprofessional exchanges. A limitation of this study was the relatively narrow window of tweet samples analysed in-depth, although the fact this was a time of peak activity and correlated with the first day of work for most new doctors in the UK means the sample is likely to be a fair representation of the hashtag use overall. A further limitation is the fact that some participants in this study may have had inaccurate or incomplete Twitter biographies and we were not able to corroborate this with other information sources.

The thematic analysis of social media posts could be further developed in future work using a variety of different topics, platforms and professional groups. This may include repeating this analysis in different calendar years or at different times of year - for example, at the time new doctors start work in the US. Future research in this area might also further explore the online personas of doctors and the role of humour in inter-professional healthcare discourse. Although this appeared in our study, the relatively small number of tweets meant that a significant analysis was not possible. Additionally, online and social media opportunities for patients to provide advice to healthcare professionals could be investigated in future work. Another possible avenue for further research is to consider how the advice offered on Twitter compares to other platforms, both on alternative social media sites, and through local onboarding procedures.

The implications of this study for medical educators is that there are rich opportunities to gain insights into key issues in professional education through the analysis of social media discourse. This study highlights that social media, and in particular microblogging, provides a distinctive platform for the support of newly qualified doctors, bringing richness, humour, immediacy and practicality to advice that seems to mirror key education issues identified elsewhere. Despite the often jovial nature of the \#tipsfornewdocs tweets analysed in this study, the posts were informative and diverse in their content and have the potential to influence an immeasurable number of newly qualified doctors. 


\section{Conclusion}

This study highlights that advice shared on Twitter using the \#tipsfornewdocs hashtag in a 2-day window comprised both professional knowledge acquisition and professional socialization. The analysis of social media posts has the potential to help medical educators understand the perceived knowledge gaps of new doctors, and the ways in which socialization into the professional might be practically supported.

Declarations of interest: All 3 authors are registered Twitter users (@Dr_A_Rashid, @ldndoc, @DoctorDeborah) but no tweets in this study were posted by them. There are no other conflicts of interest to declare.

Funding: none.

Ethical approval: A confirmation of ethical exemption letter was provided by the UCL Research Ethics Committee, on the grounds of all analysed information being publically available.

\section{References}

1. Cares AC, Hirschel D, Williams LM. Teaching About Victimization in an Online Environment: Translating in Person Empathy and Support to The Internet. Journal of Criminal Justice Education. 2014 25:4, 405-420.

2. Von Muhlen M, Ohno-Machado L. Reviewing social media use by clinicians. Journal of the American Medical Informatics Association. 2012 Sep 1;19(5):777-81.

3. Choo EK, Ranney ML, Chan TM, Trueger NS, Walsh AE, Tegtmeyer K, McNamara SO, Choi RY, Carroll CL. Twitter as a tool for communication and knowledge exchange in academic medicine: a guide for skeptics and novices. Medical Teacher. 2015 May 4;37(5):411-6.

4. General Medical Council. Doctors' use of social media. 2013. http://www.gmcuk.org/static/documents/content/Doctors_use_of_social_media.pdf (accessed 28/02/2017)

5. Dizon DS, Graham D, Thompson MA, Johnson LJ, Johnston C, Fisch MJ, Miller R. Practical guidance: the use of social media in oncology practice. Journal of Oncology Practice. 2012 Sep;8(5):e114-24.

6. Pillow MT, Hopson L, Bond M, et al. Social Media Guidelines and Best Practices: Recommendations from the Council of Residency Directors Social Media Task Force. Western Journal of Emergency Medicine. 2014;15(1):26-30. 
7. Chretien KC, Tuck MG, Simon M, Singh LO, Kind T. A digital ethnography of medical students who use Twitter for professional development. Journal of general internal medicine. 2015 Nov $1 ; 30(11): 1673-80$.

8. Junhasavasdikul D, Srisangkaew S, Sukhato K, Dellow A. Cartoons on Facebook: a novel medical education tool. Medical Education. 2017 May 1;51(5):539-40.

9. Khan R, Carroll C. snapchat as a Tool for Medical Education and Opportunity for Engagement. Chest. 2017 Oct 31;152(4):A544.

10. Kamel Boulos MN, Giustini DM, Wheeler S. Instagram and WhatsApp in health and healthcare: An overview. Future Internet. 2016 Jul 26;8(3):37.

11. Chan T, Trueger NS, Roland D, Thoma B. Evidence-based medicine in the era of social media: scholarly engagement through participation and online interaction. Canadian Journal of Emergency Medicine. 2017 Jan:1-6

12. Sterling M, Leung P, Wright D, Bishop TF. The Use of Social Media in Graduate Medical Education: A Systematic Review. Academic Medicine. 2017 Feb 21

13. Twitter URL: https://about.twitter.com/company (accessed 28/02/2017)

14. Tumasjan A, Sprenger T, Sandner P, et al. Predicting elections with Twitter: what 140 characters reveal about political sentiment. Precedings of the 4th International AAAI Conference on Weblogs and Social Media. Washington, DC: AAAI Press, 2010.

15. Giles J Blogs and tweets could predict the future. The New Scientist. 2010 206(2765): 20-21.

16. Signorini A, Segre AM, Polgreen PM. The use of Twitter to track levels of disease activity and public concern in the US during the influenza A H1N1 pandemic. PLOS ONE. 2011 May 4;6(5):e19467.

17. Hawkins JB, Brownstein JS, Tuli G, Runels T, Broecker K, Nsoesie EO, Mclver DJ, Rozenblum R, Wright A, Bourgeois FT, Greaves F. Measuring patient-perceived quality of care in US hospitals using Twitter. BMJ Quality \& Safety. 2016 Jun 1;25(6):404-13.

18. Basraon JS, Simpson D, Gupta A. Use of social media to promote continuous learning: a phased strategy for Graduate Medical Education Fellowship implementation. Journal of Patient-Centred Research and Reviews. 2015;2:69-72.

19. Thangasamy I, Leveridge M, Davies B, Stork B, Loeb S, Woo H. Pd19-09 International Urology Journal Club On Twitter-A Growing Educational Forum. The Journal of Urology. 2015 Apr 1;193(4):e395. 
20. Jalali A, Sherbino J, Frank J, Sutherland S. Social media and medical education: exploring the potential of Twitter as a learning tool. International Review of Psychiatry. 2015 Mar 4;27(2):1406.

21. Chretien KC, Kind T. Social media and clinical care: ethical, professional, and social implications. Circulation. 2013 Apr 2;127(13):1413-21.

22. Wong K, Swamy L, Jardine LD. \# TipsForNewDocs: Mentoring From Miles Away. Journal of graduate medical education. 2017 Oct;9(5):674.

23. Fogelson NS, Rubin ZA, Ault KA. Beyond likes and tweets: an in-depth look at the physician social media landscape. Clinical Obstetrics and Gynecology. 2013 Sep;56(3):495-508.

24. Bleakley A. Pre-registration house officers and ward-based learning: a new apprenticeship model. Medical Education. 2002 Jan 1;36(1):9-15.

25. Martimianakis MA, Michalec B, Lam J, Cartmill C, Taylor JS, Hafferty FW. Humanism, the hidden curriculum, and educational reform: A scoping review and thematic analysis. Academic Medicine. 2015 Nov 1;90(11):S5-13

26. Eraut M. Informal learning in the workplace. Studies in continuing education. $2004 \mathrm{Jul}$ 1;26(2):247-73.

27. Symplur URL: http://www.symplur.com/ (accessed 28/02/2017)

28. Eraut M. Developing professional knowledge and competence. Psychology Press; 1994.

29. Smith J, Granger K. Effective communicating starts with \#hellomynameis. Evidence-Based Nursing. 2016 May 27:ebnurs-2016.

30. Cave J, Goldacre M, Lambert T, Woolf K, Jones A, Dacre J. Newly qualified doctors' views about whether their medical school had trained them well: questionnaire surveys. BMC Medical Education. 2007 Oct 18;7(1):38.

31. Jen MH, Bottle A, Majeed A, Bell D, Aylin P. Early in-hospital mortality following trainee doctors' first day at work. PloS one. 2009 Sep 23;4(9):e7103.

32. Brennan N, Corrigan O, Allard J, Archer J, Barnes R, Bleakley A, Collett T, Bere D, Regan S. The transition from medical student to junior doctor: today's experiences of Tomorrow's Doctors. Medical Education. 2010 May 1;44(5):449-58.

33. Hesketh EA, Allan MS, Harden RM, Macpherson SG. New doctors' perceptions of their educational development during their first year of postgraduate training. Medical Teacher. 2003 Jan 1;25(1):67-76. 
34. Kellett J, Papageorgiou A, Cavenagh P, Salter C, Miles S, Leinster SJ. The preparedness of newly qualified doctors - Views of Foundation doctors and supervisors. Medical Teacher. 2015 Oct 3;37(10):949-54.

35. Weaver R, Peters K, Koch J, Wilson I. 'Part of the team': professional identity and social exclusivity in medical students. Medical Education. 2011 Dec 1;45(12):1220-9.

36. Vaidyanathan B. Professional socialization in medicine. Virtual Mentor. 2015 Feb 1;17(2):164

37. Alpert JM, Womble FE. Just What the Doctor Tweeted: Physicians' Challenges and Rewards of Using Twitter. Health Communication. 2016 Jul 2;31(7):824-32.

38. Forgie SE, Duff JP, Ross S. Twelve tips for using Twitter as a learning tool in medical education. Medical Teacher. 2013 Jan 1;35(1):8-14.

39. Brown J, Ryan C, Harris A. How doctors view and use social media: a national survey. Journal of Medical Internet research. 2014;16(12):e267. 
Table 1 - Inclusion criteria

\begin{tabular}{|l|}
\hline Contain the \#TipsForNewDocs hashtag \\
\hline $\begin{array}{l}\text { Be published between 00:00 } 1^{\text {st }} \text { August } 2016 \\
\text { and 23:59 } 2^{\text {nd }} \text { August 2016 }\end{array}$ \\
\hline $\begin{array}{l}\text { User is an individual (not an organisation or } \\
\text { group account) }\end{array}$ \\
\hline An original tweet (not a 'retweet') \\
\hline English language \\
\hline $\begin{array}{l}\text { *Twitter allows users to repost shared existing posts by } \\
\text { 'retweeting' them }\end{array}$ \\
\hline
\end{tabular}

Figure 1 Twitter activity for \#tipsfornewdocs hashtag 
Tweet Activity on \#TipsForNewDocs

$10 \mathrm{~K}$

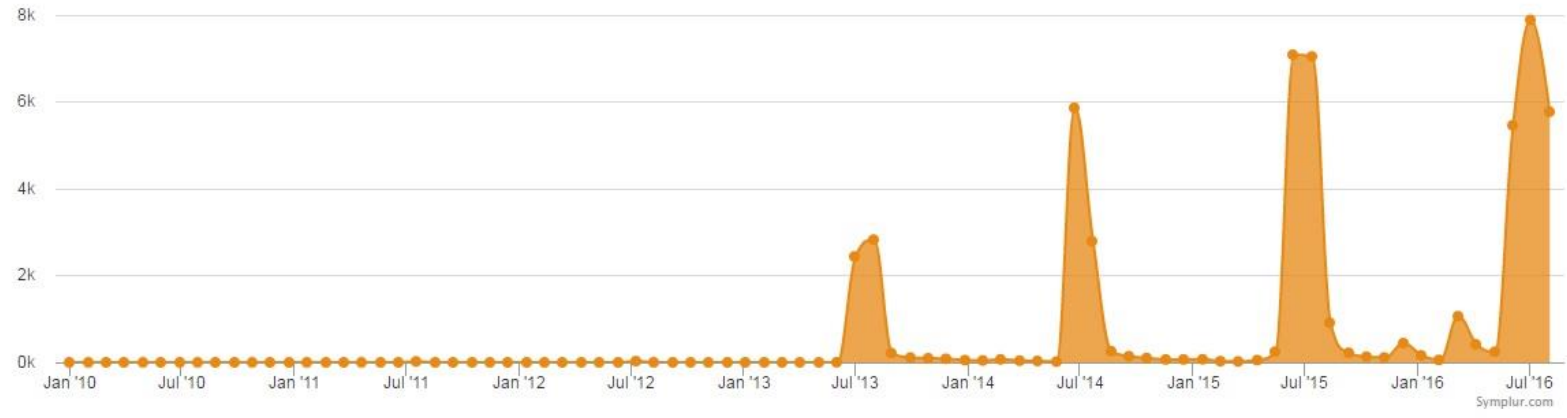

Figure 2 Summary of Included Tweets 
Tweets identified $(\mathrm{n}=$ 2742)
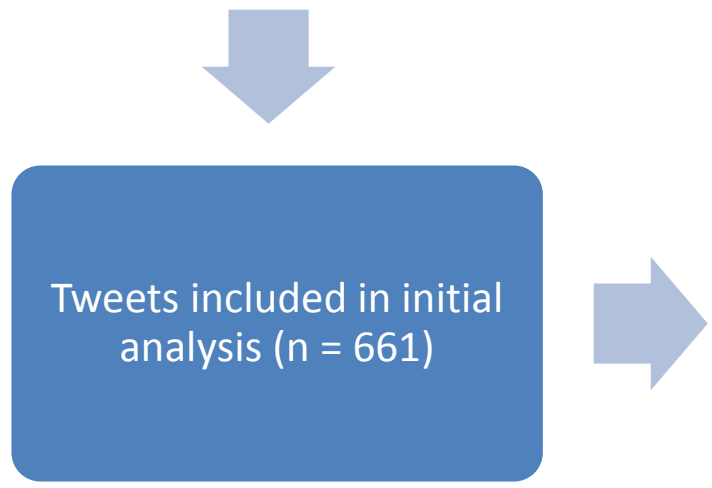

Tweets excluded $(\mathrm{n}=$ 2081)

Retweets or Tweets sent from organisation accounts
Tweets exluded $(n=6)$

Not offering advice for new doctors

Tweets included in final analysis $(n=655)$ 


\begin{tabular}{|c|c|}
\hline Person centred care & $\begin{array}{l}\text { Also remember the patient in front of you has a whole life outside of hospital which } \\
\text { is not about their illness. Ask them. (senior doctor) }\end{array}$ \\
\hline Learn from patients & $\begin{array}{l}\text { If a patient has chronic illness ask them what's been done before. Don't be afraid to } \\
\text { ask us questions. We don't bite. (patient) }\end{array}$ \\
\hline Introducing yourself & Always remember to say \#hellomynameis to patients \& the nurses! (junior doctor) \\
\hline Emotional intelligence & $\begin{array}{l}\text { Sometimes there's no right thing to do, just the least wrong thing; that's real } \\
\text { medicine for you (senior doctor) }\end{array}$ \\
\hline Ask for help & Help will always be given to those who ask for it. (senior doctor) \\
\hline $\begin{array}{l}\text { Value non-medical } \\
\text { colleagues }\end{array}$ & $\begin{array}{l}\text { If in doubt talk to the nurses. They will be your most valuable colleagues during } \\
\text { tough times as you get to grips w/the role (non-medical clinician) }\end{array}$ \\
\hline $\begin{array}{l}\text { Physical and mental } \\
\text { wellbeing }\end{array}$ & $\begin{array}{l}\text { If you find yourself with a couple of less busy minutes: eat, drink, bathroom. You } \\
\text { never know when your next break will be. (junior doctor) }\end{array}$ \\
\hline Personal values & $\begin{array}{l}\text { having in the past few wks been witness } 2 \text { both the best } \& \text { worse egs of how a dr } \\
\text { should behave, pls remember } 2 b \text { empathetic (junior doctor) }\end{array}$ \\
\hline Clinical skills & After 3 attempts at a procedure, stop and ask for help (senior doctor) \\
\hline Documentation & $\begin{array}{l}\text { If you don't document it effectively didn't happen. Write everything down! (junior } \\
\text { doctor) }\end{array}$ \\
\hline Educational opportunities & $\begin{array}{l}\text { If you don't understand what your consultant is doing/deciding on a ward round, } \\
\text { ask! We enjoy these opps for teaching (senior doctor) }\end{array}$ \\
\hline Recognising unwell patients & $\begin{array}{l}\text { If you've thought about doing that gas twice, it means you should do that gas } \\
\text { (junior doctor) }\end{array}$ \\
\hline Essential items & $\begin{array}{l}\text { Things to keep in your locker: spare pens, change of clothes, good instant coffee, } \\
\text { Oxford handbook, phone charger, snacks (junior doctor) }\end{array}$ \\
\hline Investigations and referrals & $\begin{array}{l}\text { Know why the imaging you're requesting will help diagnosis or management. You'll } \\
\text { be asked! (senior doctor) }\end{array}$ \\
\hline Getting organised & $\begin{array}{l}\text { Make a list. Put it in order of urgency/importance. Do it in that order, but be willing } \\
\text { to change it as circumstances change (junior doctor) }\end{array}$ \\
\hline Humour & $\begin{array}{l}\text { Humans are approx } 70 \% \text { water. Apart from nurses who are approx } 70 \% \text { chocolate } \\
\text { biscuits. (junior doctor) }\end{array}$ \\
\hline Good luck & Good luck to all new FY1 docs starting in \#NHSScotland (patient) \\
\hline Camaraderie & $\begin{array}{l}\text { Write a good handover to the next cohort when you leave your post in } 6 \text { or } 12 \\
\text { months. (junior doctor) }\end{array}$ \\
\hline Fitting in & Tea is very important in hospitals. (junior doctor) \\
\hline
\end{tabular}


Relationships with nonpeers when your senior colleague departs for the night + says "call me anytime," they mean the exact opposite (senior doctor)

\section{Figure 3 Key themes}

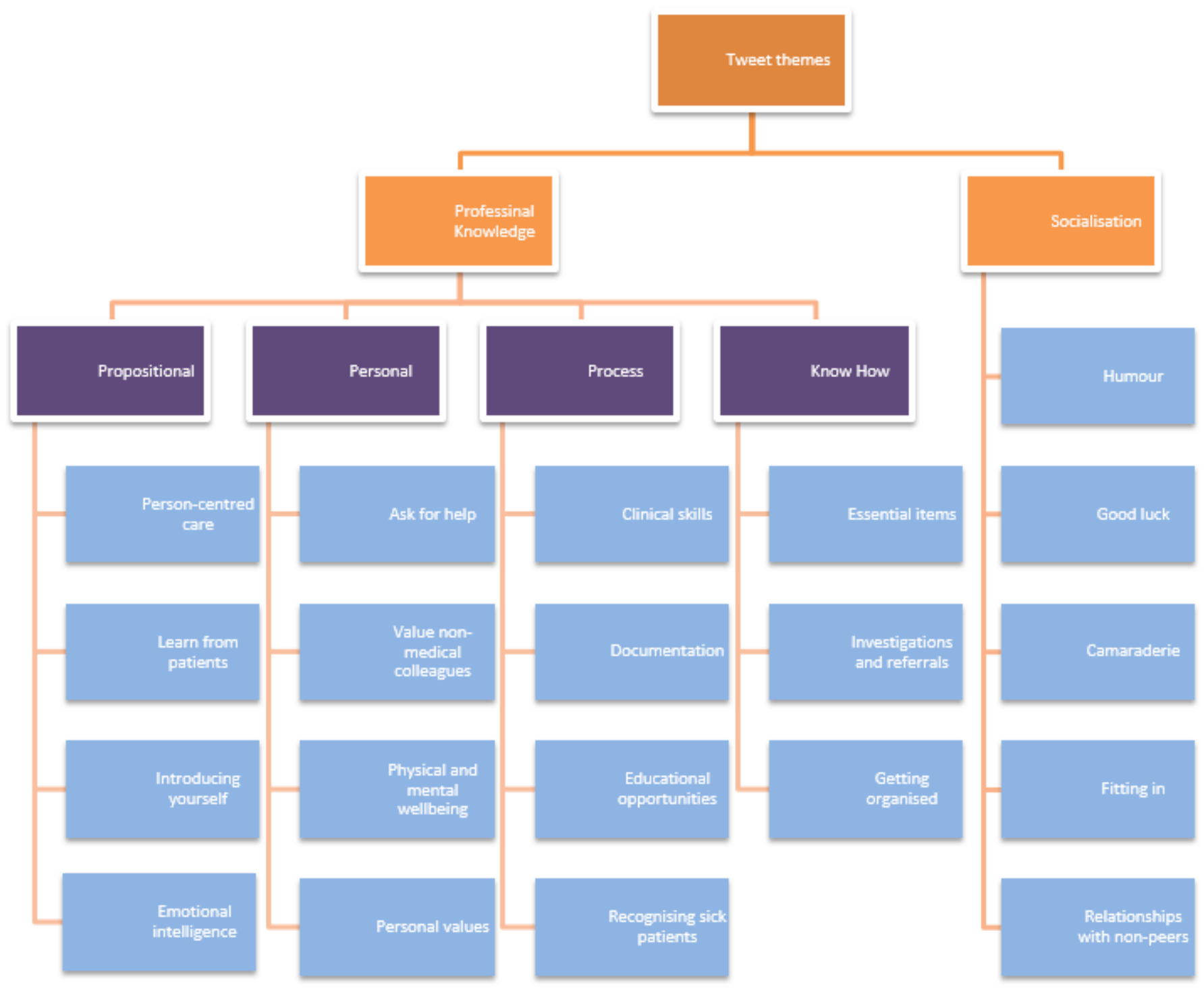

